\title{
Oroxylum indicum (L.) Kurz extract inhibits adipogenesis and lipase activity in vitro
}

Tanaporn Hengpratom ${ }^{1}$, Gordon M. Lowe ${ }^{2}$, Kanjana Thumanu', Siriporn Suknasang ${ }^{1}$, Kanokwan Tiamyom and Griangsak Eumkeb ${ }^{1 *}$ (D)

\begin{abstract}
Background: Oroxylum indicum (L.) Kurz (O. indicum) is found in Thailand. It has been used for the treatment of obesity. This study aimed to investigate the effects of an O. indicum extract (OIE) on the adipogenic and biomolecular change in 3T3-L1 adipocytes.

Methods: Initial studies examined the chemical components of OIE. The cell line 3T3-L1 was used to establish potential toxic effects of OIE during the differentiation of pre-adipocytes to adipocytes. The inhibitory effect of OIE on lipid accumulation in 3T3-L1 cells was investigated. Moreover, the impact of OIE on pancreatic lipase activity was determined. In further experiments, Fourier Transform Infrared (FTIR) was used to monitor and discriminate biomolecular changes caused by the potential anti-adipogenic effect of OIE on 3T3-L1 cells.

Results: Chemical screening methods indicated that OIE was composed of flavonoids, alkaloids, steroids, glycosides, and tannins. The percentage viability of 3T3-L1 cells was not significantly decreased after exposure to either 200 or $150 \mathrm{\mu g} / \mathrm{mL}$ of OIE for 2 and 10 days, respectively compared to control cells. The OIE exhibited a dose-dependent reduction of lipid accumulation compared to the control $(p<0.05)$. The extract also demonstrated a dosedependent inhibitory effect upon lipase activity compared to the control. The inhibitory effect of the OIE on lipid accumulation in 3T3-L1 cells was also confirmed using FTIR microspectroscopy. The signal intensity and the integrated areas relating to lipids, lipid esters, nucleic acids, glycogen and carbohydrates of the OIE-treated 3T3-L1 adipocytes were significantly lower than the non-treated 3T3-L1 adipocytes $(p<0.05)$. Principal component analysis (PCA) indicated four distinct clusters for the FTIR spectra of 3T3-L1 adipocytes based on biomolecular changes (lipids, proteins, nucleic acids, and carbohydrates). This observation was confirmed using Unsupervised hierarchical cluster analysis (UHCA).
\end{abstract}

Conclusions: These novel findings provide evidence that the OIE derived from the fruit pods of the plant is capable of inhibiting lipid and carbohydrate accumulation in adipocytes and also has the potential to inhibit an enzyme associated with fat absorption. The initial observations indicate that OIE may have important properties which in the future may be exploited for the management of the overweight or obese.

Keywords: Oroxylum indicum (L.) Kurz, Adipogenesis, Lipase activity, 3T3-L1 adipocytes, FTIR microspectroscopy, Lipid-lowering drugs

\footnotetext{
* Correspondence: griang@sut.ac.th

${ }^{1}$ School of Preclinic, Institute of Science, Suranaree University of Technology,

Nakhon Ratchasima 3000, Thailand

Full list of author information is available at the end of the article
}

(c) The Author(s). 2018 Open Access This article is distributed under the terms of the Creative Commons Attribution 4.0 International License (http://creativecommons.org/licenses/by/4.0/), which permits unrestricted use, distribution, and reproduction in any medium, provided you give appropriate credit to the original author(s) and the source, provide a link to the Creative Commons license, and indicate if changes were made. The Creative Commons Public Domain Dedication waiver (http://creativecommons.org/publicdomain/zero/1.0/) applies to the data made available in this article, unless otherwise stated. 


\section{Background}

Obesity has become a major global health problem [1]. It is a major contributor to diseases such as diabetes, cardiovascular disease and hypertension [2]. It has been established that being overweight or obese is associated with an increase in both the size and number of adipocytes along with an excessive amount of fat accumulation [3, 4]. Although using appetite suppressant drugs is a common way to treat obesity, long-term pharmacological treatment has been reported to generate many side-effects $[5,6]$. This has led to innovative research using natural products to combat obesity in the hope of a safe and novel treatment $[7,8]$.

$O$. indicum belongs to Bignoniaceae family, widely found in Tropical Asia including Thailand. The chemical composition of $O$. indicum includes baicalein, chrysin, oroxylin A and oroxylin B $[9,10]$. Many previous studies have reported antioxidant [11], anti-inflammatory [12], anti-diabetic [13] and hepatoprotective properties for $O$. indicum and its isolated compounds [14]. Animal studies suggest that $O$. indicum has few toxic effects and oral doses of $250 \mathrm{mg} / \mathrm{kg} \mathrm{BW}$ for 28 days were tolerated well in rats [13]. It has previously been demonstrated that an extract of $O$. indicum derived from the root of the plant reduced the plasma concentrations of glucose, triglycerides and total cholesterol in diabetic rats [15]. Furthermore, stem bark extracts generated an inhibitory effect on an $\alpha$-glucosidase enzyme in mature 3T3-L1 adipocytes [13]. Whilst, Oroxylin A, an isolated compound from $O$. indicum, induced both anti-adipogenesis and lipolysis in 3T3-L1 adipocytes. This was largely explained by a down-regulation of many transcriptional factors and an enhanced expression of pro-apoptotic proteins [16].

OIE has varying pharmacological properties depending on which part of the plant it is derived. In this study, we have used an extract from the fruit pods, rather than the stem of the plant which has been previously studied by several groups. The aim of this study was to provide a simple chemical composition of the extract. Initial experiments were performed using 3T3-L1 cells to establish any potential toxic effects of OIE and its impact on lipid accumulation within adipocytes. A further aim was to employ FTIR to examine the biochemical changes observed in the differentiated cells. An in vitro study was also conducted to examine the effect of OIE on pancreatic lipase. The results indicate that OIE can inhibit the development of adipocytes. Both treated and non-treated differentiated adipocytes had distinct biochemical profiles.

\section{Methods}

\section{Chemicals}

3T3-L1 mouse embryonic fibroblasts and bovine calf serum were purchased from the American Type Culture
Collection (ATCC, CL-173, USA). Insulin solution from bovine, methyl isobutyl xanthine (IBMX), lipase from porcine pancreas type 2, dimethyl sulphoxide (DMSO), 4-Nitrophenyl dodecanoate (pNP), simvastatin and orlistat were purchased from Sigma-Aldrich (St. Louis, USA). Dulbecco's modified Eagle's medium with high glucose (DMEM), penicillin, streptomycin, $\mathrm{N}$-2-hydroxyethylpiperazine-N-2-ethane sulfonic acid (HEPES) and 3-(4,5-Dimethylthiazol-2-yl)-2,5-diphenyltetrazolium bromide (MTT) were purchased from GIBCO Invitrogen (Grand Island, NY). Dexamethasone was acquired from $G$ Bioscience (St. Louis, USA). Oil Red $O$ was purchased from amresco (USA). Fetal bovine serum (FBS) was purchased from Hyclone (Logan, Utah).

\section{Preparation of $O$. indicum extract}

O. indicum (fruit pods) fresh samples were purchased from the local market at Wang Nam Khiao district, Nakhon Ratchasima province, Thailand. The voucher specimens (SOI0808U) were deposited at the flora of Suranaree University of Technology (SUT) Herbarium and authenticated by Dr.Santi Wattatana, a lecturer and a plant biologist at Institute of Science, SUT, Thailand. Fresh pods were washed thoroughly with tap water, cut into small pieces and then dried in the oven at $40{ }^{\circ} \mathrm{C}$ for 2 days. The dried pieces were pulverised using a mechanical grinder, and the resulting coarse powder was preserved from moisture. The O. indicum dry powder (500 g) was extracted with $95 \%$ ethanol by a soxhlation for $8 \mathrm{~h}$. The extract was filtered through Whatman filter paper and concentrated using a rotary evaporator at $50{ }^{\circ} \mathrm{C}$ under vacuum to remove the ethanol. The remaining extract was stored at $-80{ }^{\circ} \mathrm{C}$ until required. Subsequently, the sample was lyophilized in a freeze dryer (LABCONCO), automatic mode, vacuum $240 \times 10^{-3} \mathrm{mBar}$, and collector $-55{ }^{\circ} \mathrm{C}$. The extracted powder was stored at $20{ }^{\circ} \mathrm{C}$ until required. The lyophilized $O$. indicum extract was used within 3 months of preparation. The extract was resuspended in the differentiation medium containing $0.1 \mathrm{v} / \mathrm{v}$ DMSO (vehicle) and added to the cells at concentrations ranging from 0 to $1500 \mu \mathrm{g} / \mathrm{mL}$.

\section{Phytochemical screening}

The stock concentration of the lyophilized extract $(10 \mathrm{mg} / \mathrm{mL})$ was prepared and tested for the presence of bioactive phytochemical compounds, including total phenolics, flavonoids, alkaloids, steroids, glycosides, tannin, and saponins.

\section{Test for flavonoids}

Briefly, $1 \mathrm{~mL}$ of the OIE was mixed with $2 \mathrm{~mL}$ of $2 \% \mathrm{w} / v$ of $\mathrm{NaOH}$. A $2 \mathrm{~mL}$ aliquot of $10 \% \mathrm{w} / \mathrm{v}$ lead acetate solution was added to $1 \mathrm{~mL}$ of the alkaline extract. The 
formation of a yellow colour indicated the presence of flavonoids $[17,18]$.

\section{Test for alkaloids}

The Mayer's and Wagner's test was performed. Briefly, $1 \mathrm{~mL}$ of the OIE was added to $2 \mathrm{~mL}$ of $1 \% \mathrm{v} / \mathrm{v} \mathrm{HCl}$ and heated. A few drops of Mayer's and Wagner's reagents was added to the mixture, the presence of a precipitate suggested the presence of alkaloids in the sample $[17,18]$.

\section{Test for steroids}

The steroids containing in OIE were investigated. In short, $1 \mathrm{~mL}$ of the OIE was mixed with $2 \mathrm{~mL}$ each of chloroform and concentrated $\mathrm{H}_{2} \mathrm{SO}_{4}$. A red colour in the lower layer indicated the presence of steroids $[17,18]$.

\section{Test for glycoside}

The detection of glycosides was performed using Salkowski's test. In brief, $2 \mathrm{mg}$ of the OIE was mixed with $2 \mathrm{~mL}$ of chloroform and a few drops of concentrated $\mathrm{H}_{2} \mathrm{SO}_{4}$. A reddish brown colour was associated with the presence of glycosides $[17,18]$.

\section{Test for tannin}

The Gelatin test was performed to identify tannins in the extract. To summarise, $1 \mathrm{~mL}$ of the OIE was added to $2 \mathrm{~mL}$ of a $1 \% \mathrm{w} / v$ gelatin solution, the formation of a white precipitate indicated the presence of tannins $[17,18]$.

\section{Test for saponin}

The foam test was performed. Briefly, a $5 \mathrm{~mL}$ aliquot of the OIE was shaken for $5 \mathrm{~min}$. If saponins were present, they formed a stable foam in the test tube $[17,18]$.

\section{Total phenolic content determination (TPC)}

The total phenolic content was measured following the method outlined by Kohoude with slight modifications [19]. In brief, $20 \mu \mathrm{L}$ of extract $(0.625 \mathrm{mg} / \mathrm{mL})$ or a standard solution of gallic acid $(0-7.5 \mu \mathrm{g} / \mathrm{mL})$ were added into $100 \mu \mathrm{L}$ of Folin-Ciocalteu reagent. The mixture was incubated at room temperature for $6 \mathrm{~min}$, prior to the addition of $7.5 \% \mathrm{w} / \mathrm{v}$ of $\mathrm{Na}_{2} \mathrm{CO}_{3}$. After a $1 \mathrm{~h}$ incubation at room temperature, the absorbance was recorded at $760 \mathrm{~nm}$ against a DMSO blank. TPC of the sample was expressed as mg of gallic acid equivalents (GAE) per $g$ of dry weight.

\section{Total flavonoid content determination (TFC)}

The total flavonoid content was measured according to a previously published method with slight modifications [20]. To summarise, a $25 \mu \mathrm{L}$ of extract $(3 \mathrm{mg} / \mathrm{mL})$ or a standard solution of catechin $(0-200 \mu \mathrm{g} / \mathrm{mL})$ were added to $125 \mu \mathrm{L}$ of deionised water, followed by the addition of $10 \mu \mathrm{L}$ of $5 \% w / v \mathrm{NaNO}_{2}$. This mixture was incubated at room temperature, and after $6 \mathrm{~min}, 15 \mu \mathrm{L}$ of $10 \% \mathrm{AlCl}_{3}$ was added. Upon mixing the reaction was allowed to proceed for $5 \mathrm{~min}$, then $50 \mu \mathrm{L}$ of $1 \mathrm{M} \mathrm{NaOH}$ was added. The absorbance of the mixture was determined at $595 \mathrm{~nm}$ versus prepared DMSO blank. Total flavonoid of the sample was expressed as $\mathrm{mg}$ of catechin equivalent (CE) per g of dry weight.

\section{Cell culture and differentiation procedures}

The differentiation procedures of 3T3-L1 preadipocyte were performed as following the ATCC recommended protocol. Briefly, adherent 3T3-L1 cells were cultured in DMEM containing a high glucose concentration, supplemented with $10 \%$ of bovine calf serum, $100 \mathrm{U} / \mathrm{mL}$ of penicillin and $100 \mu \mathrm{g} / \mathrm{mL}$ of streptomycin, until they reached $70-80 \%$ confluently. Two days after confluence (day 0 ), the cells were stimulated to differentiate with differentiation medium containing 10\% FBS, $1.0 \mu \mathrm{M}$ dexamethasone, $0.5 \mathrm{mM}$ of IBMX, and $1.0 \mu \mathrm{g} / \mathrm{mL}$ of insulin in DMEM. On day 2, the differentiation medium was changed to maintain a medium consisting of $10 \%$ of FBS and $1.0 \mu \mathrm{g} / \mathrm{mL}$ of insulin in DMEM. The maintenance medium was replaced every $48 \mathrm{~h}$ for the next 8 days. On day 10, the differentiation of 3T3-L1 pre-adipocytes into adipocytes was observed. The cells were maintained in $5 \% \mathrm{CO}_{2}$ incubator and at $37{ }^{\circ} \mathrm{C}$ throughout the whole process. The required doses of OIE were added to the 3T3-L1 cell culture during the differentiation (at day $0,2,4,6$, and day 8 ).

\section{Cytotoxicity assay}

The cytotoxic effects of the OIE on the proliferation of preadipocytes and adipocytes were determined by MTT assay largely following the method of Dunkhunthod et al. and Denizot $[21,22]$. In brief, the 3T3-L1 cells were seeded in 96-well plates at a density of $5 \times 10^{3}$ cells/well. Two days after reaching confluence, the dividing cells were treated with the OIE at concentrations ranging from 0 to $1500 \mu \mathrm{g} / \mathrm{mL}$. Both treated and control cells were incubated for a further $48 \mathrm{~h}$. At the end of the treatment period, the cell viability was assessed by using the MTT assay. The culture medium was removed, and $100 \mu \mathrm{L}$ of MTT solution $(0.5 \mathrm{mg} / \mathrm{mL}$ in phosphate buffer saline) was added, then incubated at $37^{\circ} \mathrm{C}$ for $4 \mathrm{~h}$. After incubation, $150 \mu \mathrm{L}$ of DMSO was added to dissolve formazan crystal. The absorbance of the intracellular formazan is proportional to the number of viable cells present was determined at $540 \mathrm{~nm}$ against a blank medium (Benchmark Plus, Bio-Rad, Japan). The percentage of formazan product was calculated to determine cytotoxicity [23]. OIE at concentrations of $0-200 \mu \mathrm{g} / \mathrm{mL}$ were used to assess any cytotoxic effects of mature 
adipocytes and Oil Red $\mathrm{O}$ assay for lipid accumulation. The $\mathrm{IC}_{50}$ of the extract was also calculated from a dose-response curve using linear regression analysis.

\section{Oil red $O$ staining}

The intracellular triglyceride content was determined using an Oil Red $\mathrm{O}$ staining method as previously described [21, 24]. Briefly, on day 10, cells were washed with PBS and fixed with $1 \mathrm{~mL} /$ well of $10 \%(\mathrm{v} / \mathrm{v})$ formalin for $1 \mathrm{~h}$ at room temperature. After fixation, the cells were washed, and $500 \mu \mathrm{L}$ of $0.5 \%$ of the Oil Red O solution was added. The cells were incubated for $30 \mathrm{~min}$ at room temperature. The Oil Red O solution was removed by gentle aspiration, and the cells were washed with PBS. The nucleus was then stained with $0.10 \%(w / v)$ haematoxylin. Fat droplets were observed under an inverted microscope at an appropriate magnification. To determine the percent of lipid accumulation, the cells were extracted with $250 \mu \mathrm{L}$ of isopropanol and $200 \mu \mathrm{L}$ of the eluted solution was transferred to a new 96 well plate. The absorbance was measured at $490 \mathrm{~nm}$ with a microplate spectrophotometer. The simvastatin at $1.67 \mu \mathrm{g} / \mathrm{mL}$ was used as a positive control. The 3T3-L1 cells, treated with $200 \mu \mathrm{g} / \mathrm{mL}$ OIE were selected for FTIR studies.

\section{Fourier-transform infrared spectroscopy}

The effect of OIE on 3T3-L1 adipocyte cells using FTIR measurement was performed following the method of Dunkhunthod et al. [21]. Briefly, on day 10, cells were collected and centrifuged at $4000 \times g$ for $5 \mathrm{~min}$, the medium was removed by gentle aspiration, and the cells were agitated and washed with $0.85 \% w / v \mathrm{NaCl}$. The cell suspensions were centrifuged at $4000 \times g$ for $5 \mathrm{~min}$. The acquired cell pellets were dropped onto a window slide (MirrIR, Kevley Technologies) and dried for $30 \mathrm{~min}$ in a desiccator to eliminate the excess water. The dried cells were stored in a desiccator prior to FTIR analysis.

FTIR spectra were obtained at the Synchrotron Light Research Institute (Public Organization), Thailand. FTIR spectra were acquired with a Bruker Vertex 70 spectrometer coupled with a Bruker Hyperion 2000 microscope (Bruker Optics Inc., Ettlin-Gen, Germany) equipped with nitrogen cooled MCT ( $\mathrm{HgCdTe})$ detector with a $36 \mathrm{x}$ IR. The spectra were obtained in the reflection mode with the wavenumber range of 4000$600 \mathrm{~cm}^{-1}$, using an aperture size of $50 \mu \mathrm{m} \times 50 \mu \mathrm{m}$, with a resolution of $6 \mathrm{~cm}^{-1}$. Each spectrum was produced following 64 scans. OPUS 7.2 software (Bruker Optics Ltd., Ettlingen, Germany) was used to acquire FTIR spectral data and control instrument system.

The spectral ranges of biochemical interest were identified using Principal Component Analysis (PCA) as being between 3000 and $2800 \mathrm{~cm}^{-1}$ and $1800-850 \mathrm{~cm}^{-1}$.
The preprocessing of the spectra was performed by second derivative transformations using the Savitzky-Golay algorithm (nine smoothing points) and normalised with extended multiplicative signal correction (EMSC). Score plots (3D) and loading plots were used to represent the different classes of data and relations among variables of the data set, respectively.

The FTIR spectra datasets were submitted for Unsupervised Hierarchical Cluster Analysis (UHCA), to collect similar spectra in groups or clusters, using the OPUS 7.2 software (Bruker). Cluster analysis was performed on the second derivatives, and vector normalises spectra using Ward's algorithm.

\section{Lipase activity}

Measurement of lipase activity was performed as previously described by Guo et al. and Dunkhunthod et al. $[21,25]$. In brief, lipase of porcine pancreas type 2 was dissolved in distilled water at $5 \mathrm{mg} / \mathrm{mL}$, the solution was centrifuged at 10,000 $x g$ for $5 \mathrm{~min}$, and the supernatant was used for the assay. A $0.1 \% w / v$ solution of pNP laurate was prepared in $5 \mathrm{mM}$ of sodium acetate $(\mathrm{pH}$ 5.0) containing $1 \% v / \mathrm{v}$ Triton $\mathrm{X}-100$. The solution was heated to $80{ }^{\circ} \mathrm{C}$ and cooled to room temperature prior to use. A $30 \mu \mathrm{L}$ volume of the lipase was added to a 96 well plate, followed by $40 \mu \mathrm{L}$ of reaction buffer $(100 \mathrm{mM}$ of Tris buffer $\mathrm{pH}$ 8.2). Either $20 \mu \mathrm{L}$ of OIE or $50 \% \mathrm{v} / \mathrm{v}$ DMSO was added prior to the addition $30 \mu \mathrm{L}$ of the substrate solution. The mixtures were incubated at $37{ }^{\circ} \mathrm{C}$ for $6 \mathrm{~h}$ and measured at $409 \mathrm{~nm}$ using a microplate spectrophotometer. Orlistat at 12.5 to $100 \mu \mathrm{g} / \mathrm{mL}$ was used as a positive control. The inhibition rate (\%) was calculated using the following equation. [((OD control blank control $)-(\mathrm{OD}$ sample - blank sample $)) / O D$ control $] \times$ 100 [26].

\section{Statistical analysis}

All the data were expressed as a mean \pm standard error of the mean (SEM). The statistical significances difference between treatment and control groups of cell viability, the amount of lipid accumulation, biomolecular changes, and lipase activity were analysed by One-way analysis of variance (ANOVA) with a Turkey's HSD post-hoc test (SPSS $\mathrm{v} 23$ ). Values were considered statistically significant when $p<0.05$ and data were representative of at least three independent experiments $(n \geq 3)$. Most experiments were performed in triplicate.

\section{Results}

The phytochemical composition, TPC, and TFC

A $1.0 \mathrm{Kg}$ weight of fruit pods from $O$. indicum was processed to obtain a final yield of $18.41 \%(w / w)$ OIE (Table 1). Qualitative tests revealed that the extract contained flavonoids, alkaloids, steroids, glycoside, and 
Table 1 Extraction yield and phytochemical composition of Oroxylum indicum fruit extract. Extraction yield, total phenolic content, total flavonoid content and phytochemical composition of Oroxylum indicum fruit extract

\begin{tabular}{|c|c|c|c|c|c|c|c|c|c|c|}
\hline Sample & Fresh weight (g) & Dry weight (g) & Yield (g) & Yield (\%w/w) & Flavonoids & Alkaloids & Steroids & Glycoside & Tannins & Saponin \\
\hline Oroxylum indicum & 1000 & 133.40 & 24.53 & 18.41 & + & + & + & + & + & - \\
\hline \multicolumn{2}{|c|}{ Total phenolic content (TPC) } & \multicolumn{9}{|c|}{$51.48 \pm 0.77(\mathrm{mg} \mathrm{GAE} / \mathrm{g})^{\mathrm{a}}$} \\
\hline \multicolumn{2}{|c|}{$\begin{array}{l}\text { Total flavonoids content } \\
\text { (TFC) }\end{array}$} & \multicolumn{9}{|c|}{$34.19 \pm 2.47(\mathrm{mg} \mathrm{CE} / \mathrm{g})^{a}$} \\
\hline
\end{tabular}

$(+)=$ positive test; $(-)=$ negative test

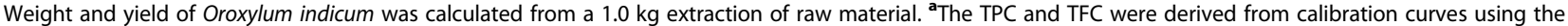
relevant standard and based on dry weight of Oroxylum indicum. The data are expressed as the mean \pm SEM of three independent experiments performed in triplicate $(n=9)$

tannins, but no saponins were detected. The concentration of TPC and TFC present in OIE were $51.483 \pm$ $0.766 \mathrm{mg} \mathrm{GAE} / \mathrm{g}$ and $34.191 \pm 2.473 \mathrm{mg} \mathrm{CE} / \mathrm{g}$ of dry weight, respectively (Table 1).

\section{The effect of OIE on the viability of pre- and mature adipocytes}

To evaluate the cytotoxicity of OIE on both non-differentiated and differentiated 3T3-L1 cells, an MTT assay was conducted. A concentration of OIE between 250 to $1500 \mu \mathrm{g} / \mathrm{mL}$ showed a significant reduction $(p<0.05)$ in the viability of pre-adipocytes (Fig. 1). However, the viability of cells treated with lower doses of the extract (50 to $200 \mu \mathrm{g} / \mathrm{mL}$ ) was not significantly different compared to non-treated cells $(p>0.05)$. The $\mathrm{IC}_{50}$ at $48 \mathrm{~h}$ for pre-adipocytes was $882.68 \pm 47.99 \mu \mathrm{g} / \mathrm{mL}$. These results suggest that doses of the OIE above $250 \mu \mathrm{g} / \mathrm{mL}$ are detrimental to pre-adipocytes viability. In the light of this observation, all subsequent experiments to investigate mature adipocyte viability used a dose of $200 \mu \mathrm{g} /$ $\mathrm{mL}$ or less.

The effect of the OIE on mature adipocytes indicated that doses of OIE at 50 to $200 \mu \mathrm{g} / \mathrm{mL}$ did not reduce the viability of mature cells compared to the control $(p>$ 0.05) over a 10 day period (Fig. 2).

\section{The effect of OIE on adipocyte differentiation and lipid accumulation}

During the differentiation of 3T3-L1 preadipocytes to adipocytes, the cells were treated with OIE, and the intracellular lipid concentration was determined using Oil Red O staining. The 3T3-L1 pre-adipocytes when exposed to the differentiation medium resulted in a significant increase of lipid accumulation in comparison to pre-adipocytes $(p<0.05)$ (Fig. 3). However, the addition of OIE at $200 \mu \mathrm{g} / \mathrm{mL}$ significantly decreased the

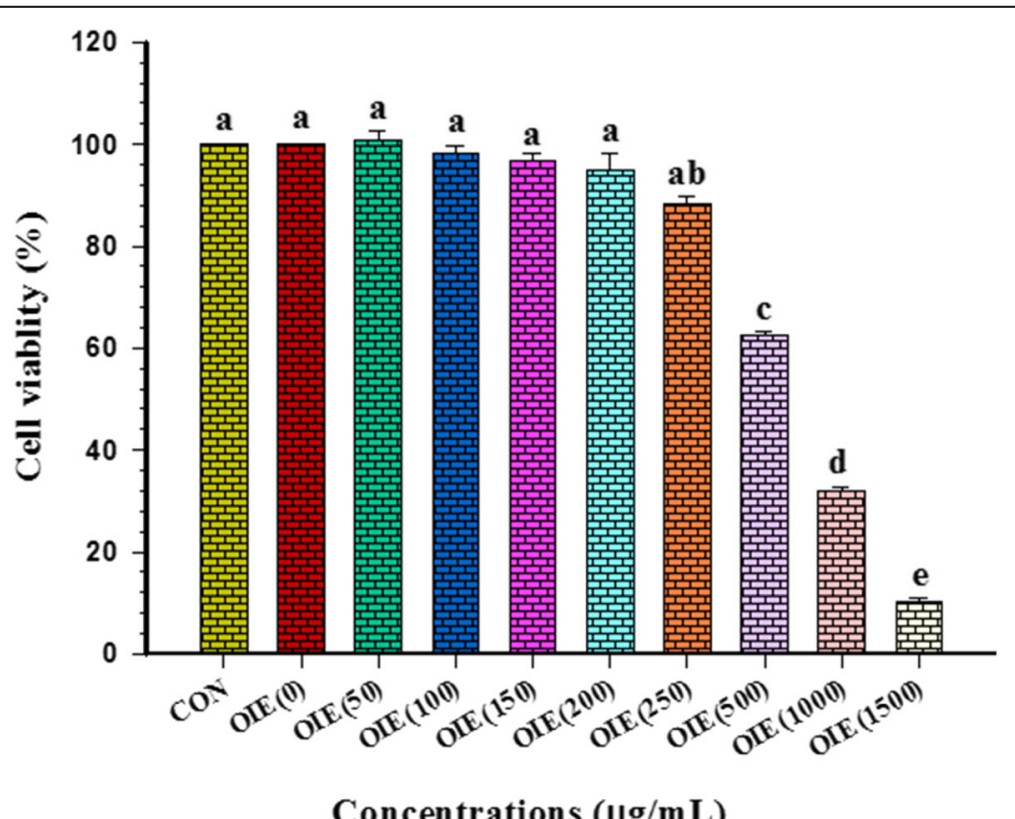

Fig. 1 Graphically represents the effect of Oroxylum indicum extract on the viability of 3T3-L1 preadipocytes. CON=vehicle control; OIE(50)= Oroxylum indicum at $50 \mu \mathrm{g} / \mathrm{mL}$. Values are Means \pm SEM ( $n=3$ replicates). A significant differences were observed (Tukey's HSD test, $p<0.05)$ and are represented on the figure with letters from a to e. Bars annotated with the differrent letters are significantly different to the control 


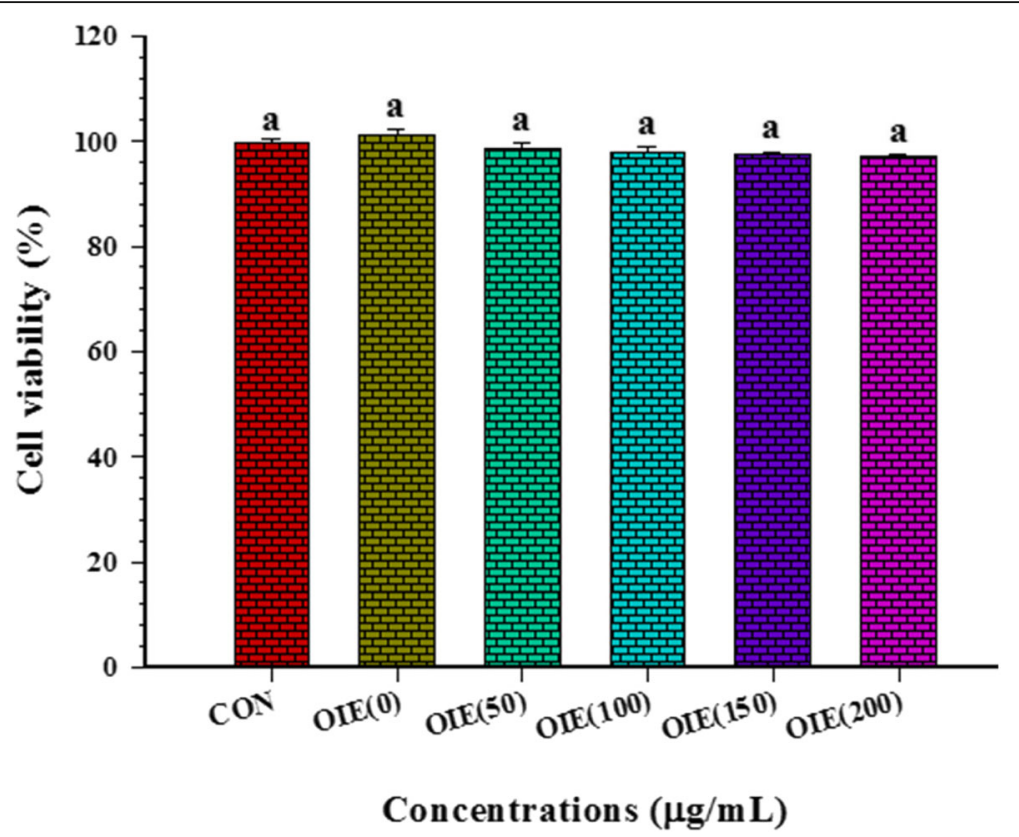

Fig. 2 Graphically represents the effect of Oroxylum indicum extract on the viability of 3T3-L1 mature adipocytes. CON=vehicle control; OIE(50)= Oroxylum indicum at $50 \mathrm{\mu g} / \mathrm{mL}$. Values are Means \pm SEM ( $n=3$ replicates). For all treatments no significant differences were observed (Tukey's HSD test, $p<0.05)$

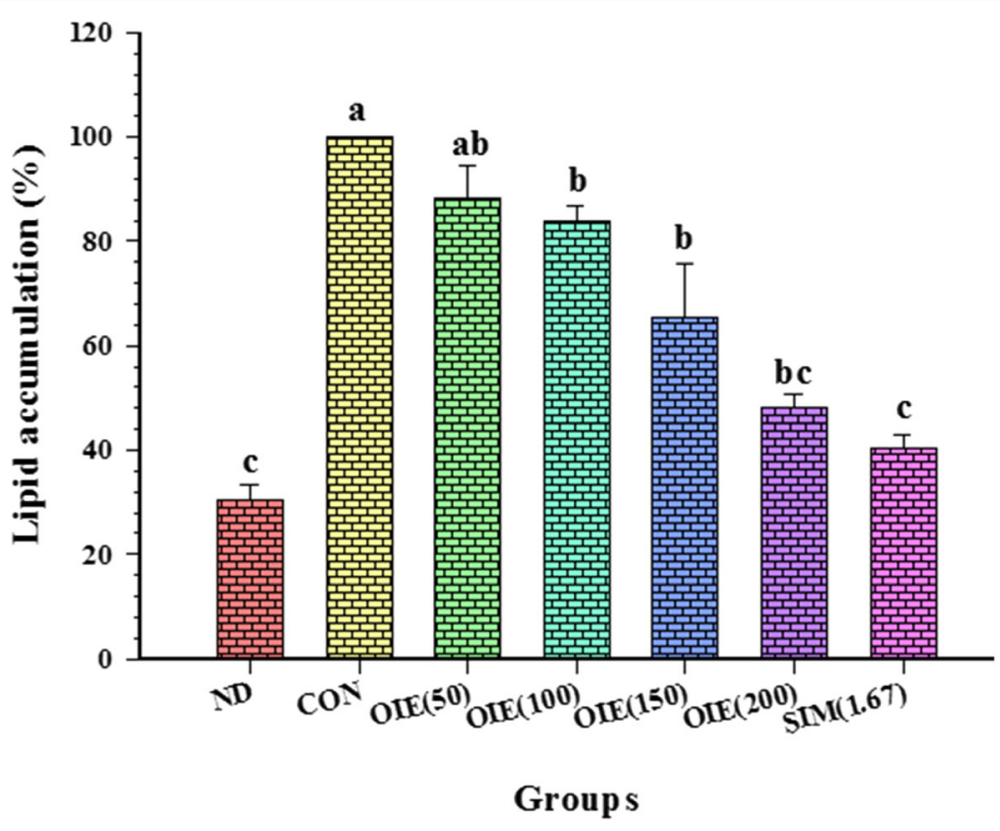

Fig. 3 The effect of Oroxylum indicum extract on the accumulation of triglycerides in 3T3-L1 differentiated cells. ND = non-differentiated cells (pre-adipocytes); $\mathrm{CON}=$ vehicle control; OIE(50) = Oroxylum indicum at $50 \mu \mathrm{g} / \mathrm{mL}$. SIM(1.67) = Simvastatin at $1.67 \mu \mathrm{g} / \mathrm{mL}$ (a positive control). Values are Means \pm SEM ( $n=3$ replicates). A significant differences were observed (Tukey's HSD test, $p<0.05)$ and are represented on the figure with letters from a to $c$ 
intracellular lipid accumulation by approximately $52 \%$, compared to the 3T3-L1 adipocyte (control) $(p<0.05)$. The $\mathrm{IC}_{50}$ and $\mathrm{IC}_{60}$ values for OIE on lipid accumulation were determined to be $201.26 \pm 10.00$ and $237.72 \pm 14.96 \mu \mathrm{g} / \mathrm{mL}$, respectively. In addition, the cholesterol-lowering drug, simvastatin exhibited an $\mathrm{IC}_{60}$ at a concentration of $1.67 \mu \mathrm{g} /$ $\mathrm{mL}$. The effect of simvastatin is 142 times greater than OIE.

In order to gain more evidence that OIE could affect lipid accumulation in differentiated 3T3-L1 cells, pre-adipocytes and adipocytes were stained with Oil Red $\mathrm{O}$ and heamatoxylin and observed a light microscope (Fig. 4). Untreated adipocytes displayed an increase in size and number of prominent lipid droplets (Fig. 4b). Whilst adipocytes treated with simvastatin exhibited very

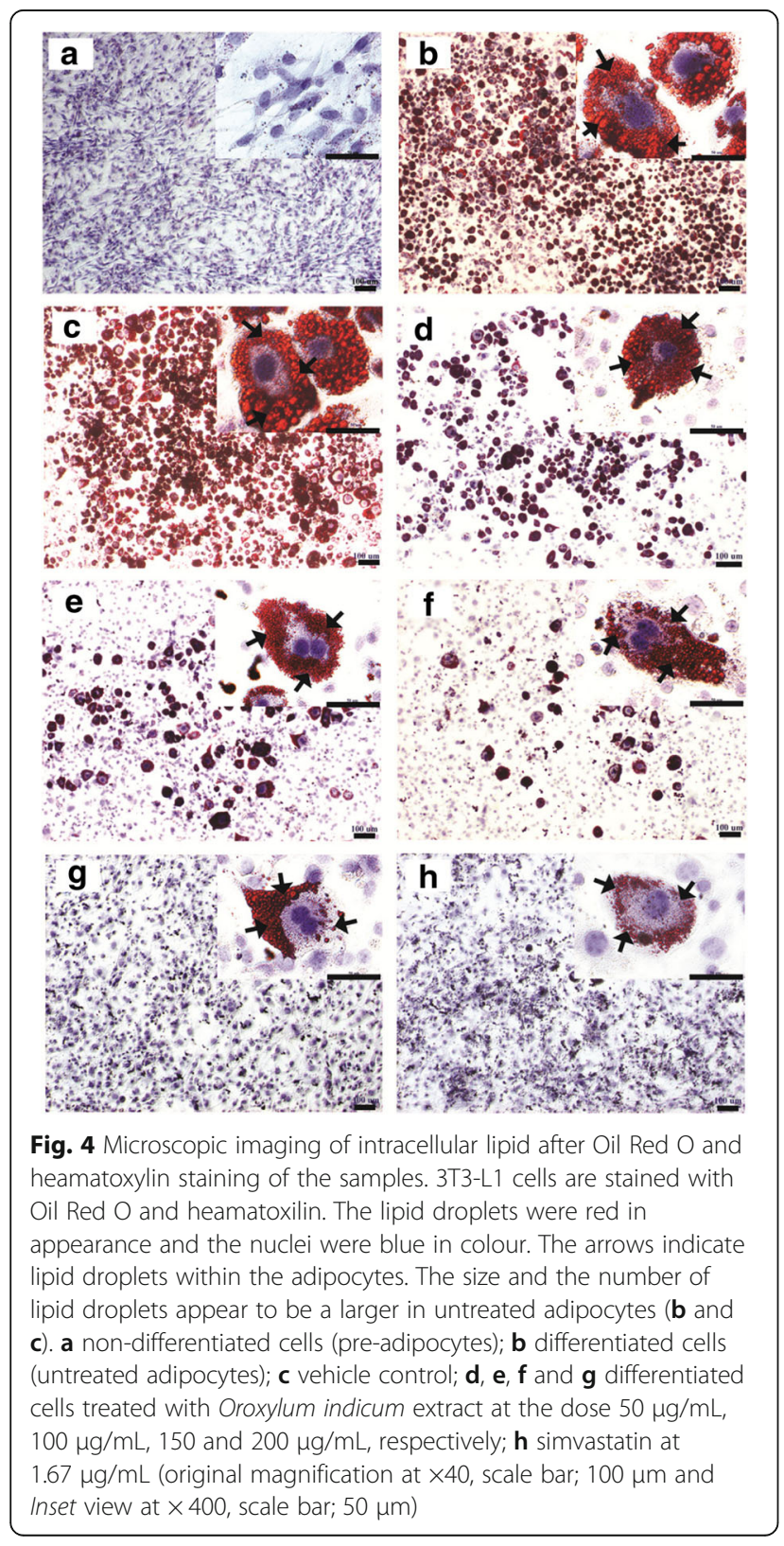

small and diffuse lipid droplets (Fig. 4h). The $200 \mu \mathrm{g} / \mathrm{mL}$ OIE treated adipocytes displayed smaller size and number of lipid droplets that seemed to be focused on one part of the cell (Fig. 4g).

\section{FTIR spectra profiles}

FTIR microspectroscopy was used to determine the biochemical composition of pre-adipocytes, adipocytes, and adipocytes treated with either, simvastatin or OIE. For each treatment FTIR spectra between wavelengths 3000-950 $\mathrm{cm}^{-1}$ were obtained (Fig. 5). The Spectra were converted to second order derivatives to allow a more detailed comparison of the different treatments to the cells (Table 2). The spectra were separated into three distinct areas: (1) lipids (3000-2800 $\left.\mathrm{cm}^{-1}\right)$, (2) proteins (1700-1500 $\mathrm{cm}^{-1}$ ) and (3) carbohydrate and nucleic acids $\left(1300-950 \mathrm{~cm}^{-1}\right)$.

\section{The second derivative spectra in the lipid region}

The spectra in the high-frequency region at 3000$2800 \mathrm{~cm}^{-1}$ correspond to the symmetrical and asymmetrical vibrations of $-\mathrm{CH}$ groups of the lipid content [27]. The average second derivative spectra of 3T3-L1 cells under different experimental conditions exhibited three characteristic regions at $2962 \mathrm{~cm}^{-1}, 2924 \mathrm{~cm}^{-1}$ and $2854 \mathrm{~cm}^{-1}$ which are associated with cellular lipids. Each area is produced as a result of asymmetrical stretching from the methyl and methylene groups of lipids, and also the symmetrical stretching from methylene groups of lipids (Fig. 6a). Further evidence for the presence of lipids occurred at the lower wavenumber region at $1740 \mathrm{~cm}^{-1}$, which is assigned to $\mathrm{C}=\mathrm{O}$ stretches of the ester functional groups from lipids and fatty acids (Fig. 6b) [28]. The relative absorbance at $2924 \mathrm{~cm}^{-1}$ and $1740 \mathrm{~cm}^{-1}$ of adipocyte were stronger than the treated cells or pre-adipocytes (Fig. 6a and b). To discriminate between non treated and treated adipocytes the ratio of the integrated area of several functional groups was calculated. The selected regions were $\mathrm{CH}_{2}$ (2938$2906 \mathrm{~cm}^{-1}$, centred at $\left.2924 \mathrm{~cm}^{-1}\right) / \mathrm{CH}_{3}$ (2973$2954 \mathrm{~cm}^{-1}$, centred at $2962 \mathrm{~cm}^{-1}$ ) [29, 30]. The selection of these area was made as they are associated with asymmetric stretching of lipids. The results showed that the ratio of integrated area of the lipids region in the OIE-treated adipocytes displayed significantly less than the untreated adipocytes group $(p<0.05)$ and did not significant from a simvastatin-treated group $(p>$ 0.05) (Fig. 7a). Another useful parameter was the integrated area of the ester functional groups from lipids at $1740 \mathrm{~cm}^{-1}$ in the OIE-treated adipocytes group indicated significantly lower than the untreated adipocytes group $(p<0.05)$ (Fig. $6 \mathrm{~b}$ and $7 \mathrm{a})$. 


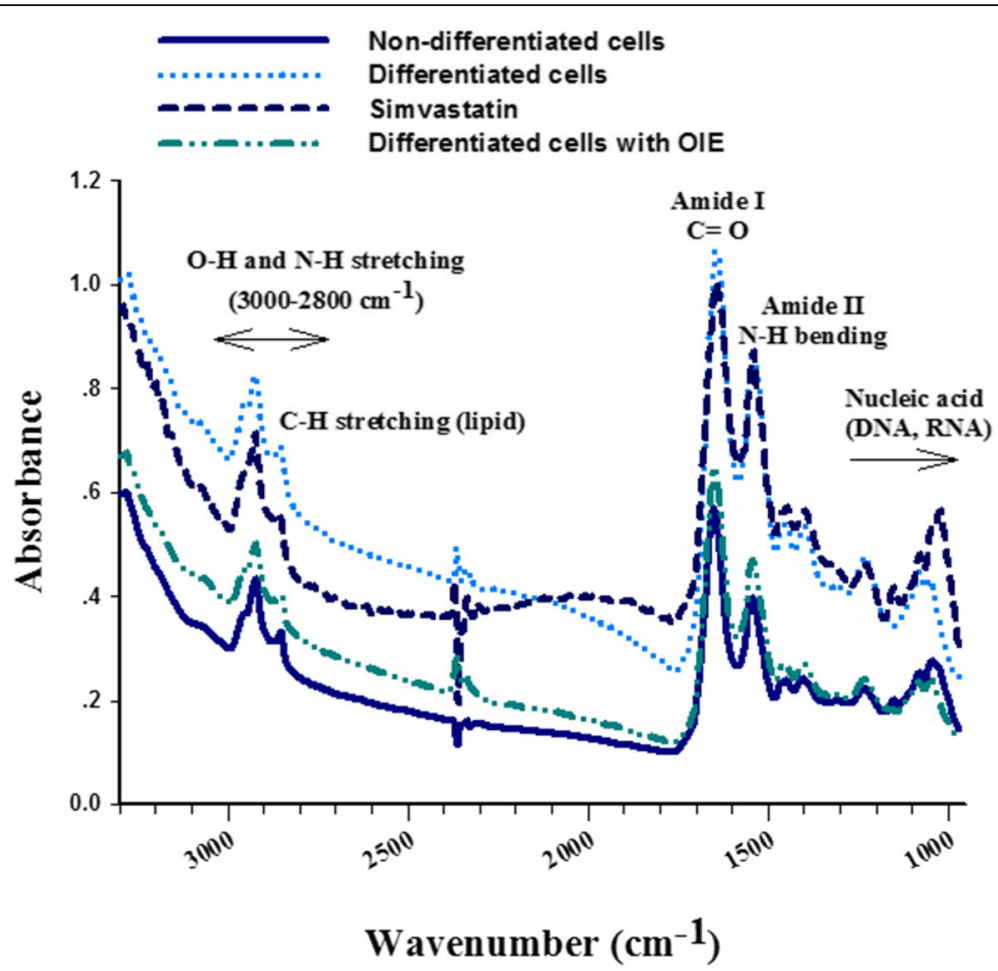

Fig. 5 Average original FTIR spectra (3000-950 $\mathrm{cm}^{-1}$ ) obtained from 3T3-L1 cells. The raw spectra of non-differentiated cells (preadipopcytes) (n $=62)$, differentiated cells $(n=92)$, simvastatin and Oroxylum indicum extract treated 3T3-L1 adipocytes $(n=47)$ after 10 days

Table 2 FTIR band assignments for functional groups found in the second derivative spectra of 3T3-L1 cells $[27,28]$

\begin{tabular}{|c|c|}
\hline $\begin{array}{l}\text { 2nd derivative } \\
\text { spectra }\left(\mathrm{cm}^{-1}\right)\end{array}$ & Band assignment \\
\hline 2962 & $\begin{array}{l}\text { Asymmetrical stretching }(\mathrm{C}-\mathrm{H}) \text { from methyl }\left(-\mathrm{CH}_{3}\right) \\
\text { groups of lipids }\end{array}$ \\
\hline 2924 & $\begin{array}{l}\text { Asymmetrical stretching }(\mathrm{C}-\mathrm{H}) \text { from methylene } \\
\left(-\mathrm{CH}_{2}\right) \text { groups of lipids }\end{array}$ \\
\hline 2854 & $\begin{array}{l}\text { Symmetrical stretching }(\mathrm{C}-\mathrm{H}) \text { from methylene } \\
\left(-\mathrm{CH}_{2}\right) \text { groups of lipids }\end{array}$ \\
\hline 1740 & $\begin{array}{l}(\mathrm{C}=\mathrm{O}) \text { of ester functional groups primarily from } \\
\text { lipid and fatty acids }\end{array}$ \\
\hline 1647 & Amide I protein ( $\mathrm{C}=\mathrm{O}$ stretching) \\
\hline 1543 & Amide II protein ( $\mathrm{N}-\mathrm{H}$ bending, $\mathrm{C}-\mathrm{H}$ stretching) \\
\hline 1462 & $\begin{array}{l}\text { Asymmetrical deformation }\left(\mathrm{CH}_{2}\right)_{\text {scissor }} \\
\text { from methylene }\left(-\mathrm{CH}_{2}\right) \text { groups of lipids }\end{array}$ \\
\hline 1400 & $\begin{array}{l}\text { Symmetrical stretching }\left(\mathrm{COO}^{-}\right) \text {associated } \\
\text { with symmetrical in-plane deformation bend } \\
\left(\mathrm{CH}_{3}\right) \text { of proteins }\end{array}$ \\
\hline 1234 & $\begin{array}{l}\text { Asymmetrical stretching }\left(\mathrm{PO}_{2}^{-}\right) \text {mainly nucleic acids } \\
\text { with the little contribution from phospholipids }\end{array}$ \\
\hline 1153 & $\begin{array}{l}\text { Asymmetrical stretching (CO-O-C) of glycogen, } \\
\text { other carbohydrates and nucleic acids }\end{array}$ \\
\hline 1080 & $\begin{array}{l}\text { Symmetrical stretching }\left(\mathrm{PO}_{2}^{-}\right) \text {of the } \\
\text { phosphodiester backbone of nucleic acids (DNA } \\
\text { and RNA) and phospholipids }\end{array}$ \\
\hline 1018 & (C-O) vibration from glycogen and other carbohydrates \\
\hline
\end{tabular}

The second derivative spectra in the protein region Spectra in the areas from 1700 to $1500 \mathrm{~cm}^{-1}$ are attributed to an absorption peak of proteins amide I and II. The ratio of the integrated area of several proteins related functional groups, including $\mathrm{CH}_{2}$ asymmetric stretching (2938-2906 $\mathrm{cm}^{-1}$, centred at $2924 \mathrm{~cm}^{-1}$ )/amide I (1674$1624 \mathrm{~cm}^{-1}$, centred at $1647 \mathrm{~cm}^{-1}$ ) was calculated for control and treated adipocytes. In this case there no significant difference between non treated adipocytes and OIE treated adipocytes $(p>0.05)$ (Fig. 7b) [31].

\section{The second derivative spectra in the carbohydrate and nucleic acid region}

$\mathrm{C}-\mathrm{O}$ vibrations attributed to glycogen and other carbohydrates were identified at wavelengths of $1153 \mathrm{~cm}^{-1}$ and $1018 \mathrm{~cm}^{-1}$ [32]. These signal intensity and integral area of the OIE-treated adipocytes displayed significantly less than untreated adipocytes $(p<0.05)$ but not significant different from simvastatin-treated group (Fig. 7b).

The functional group of $\mathrm{PO}_{2}$ stretching mode from mainly nucleic acids was located at $1234 \mathrm{~cm}^{-1}$ and $1080 \mathrm{~cm}^{-1}$. In this case, the OIE-treated adipocytes displayed signal intensity and integral area significantly less than the untreated and simvastatin-treated adipocytes $(p<0.05)$ (Fig. 6b and 7b) [27]. 


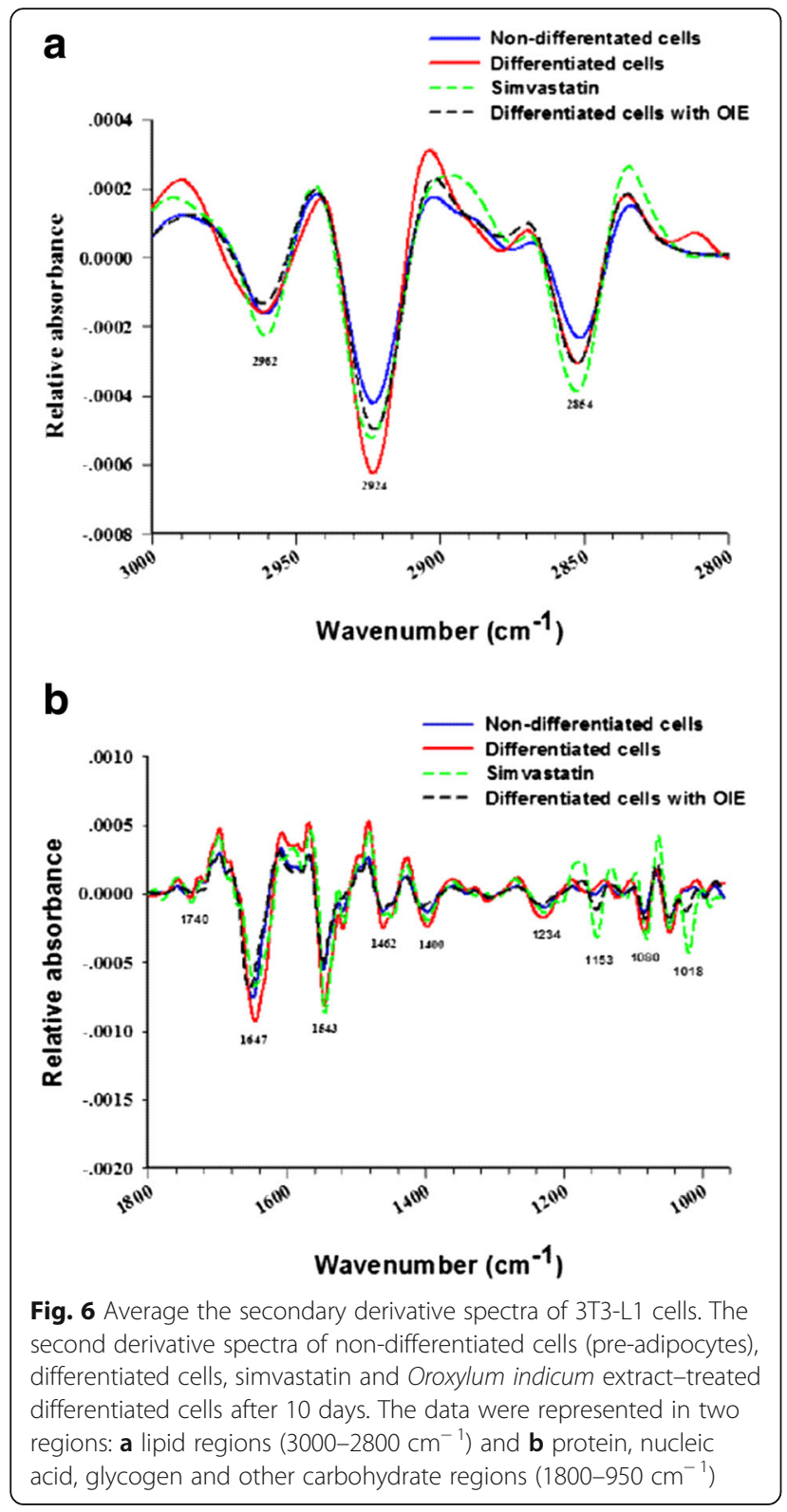

\section{PCA}

Principal Component Analysis (PCA) was performed to further discriminate data acquired from pre-adipocyte, untreated adipocyte, simvastatin- and OIE-treated adipocytes using FTIR. The PCA results were obtained from second-order derivative spectra at $3000-2800 \mathrm{~cm}^{-1}$ and 1700-950 $\mathrm{cm}^{-1}$. The results from 2-dimensional PCA clustering (Fig. 8a) clearly reveal district separation of differentiated adipocytes from treated adipocytes. The OIE and simvastatin-treated adipocytes would appear to have similar properties. Also, the spectrum band which most influences to the clustering can be examined through the PCA loading plots (Fig. 8b). PC1 loading plot was discriminated by the loading spectra at $2920 \mathrm{~cm}^{-1}$ and $2850 \mathrm{~cm}^{-1}$ caused by the C-H

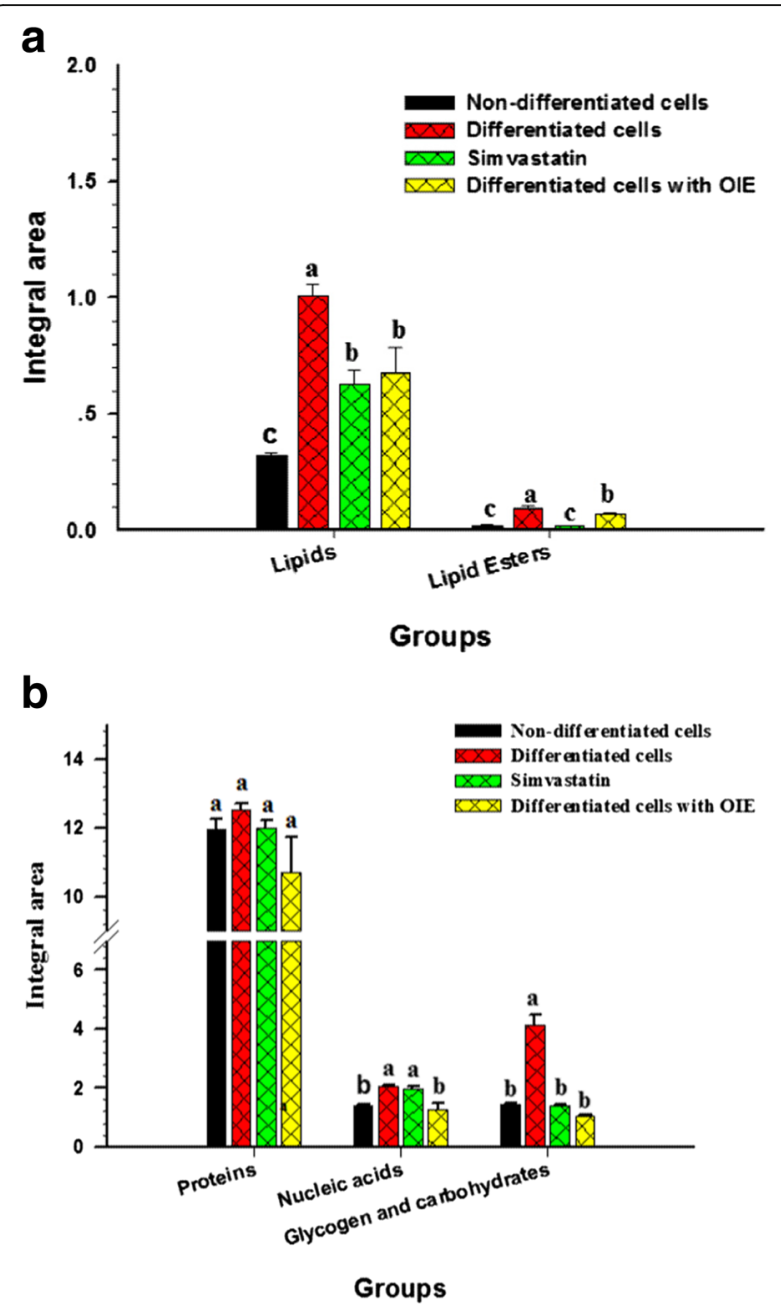

Fig. 7 The histogram of integrated areas of 3T3-L1 cells. The integrated area from second derivative data of non-differentiated cells (pre-adipocytes), differentiated cells, simvastatin- and Oroxylum indicum extract-treated differentiated cells. Integral area of lipids and lipid esters (a). Integral area of proteins, nucleic acids, glycogen and carbohydrates (b). The results reported as means \pm SEM $(n=3)$. Significant differences were observed (Tukey's HSD test, $p<0.05$ ) and are represented on the figure with letters from a to $c$

stretching, and at $1153 \mathrm{~cm}^{-1}$ and $1022 \mathrm{~cm}^{-1}$ resulting from the $\mathrm{C}-\mathrm{O}$ vibrations from glycogen and other carbohydrate [33], which separated the negative score plot of the untreated adipocytes from the positive score plot of simvastatin- and OIE-treated adipocytes These results illustrated and confirmed that untreated adipocytes had a higher lipid and carbohydrate contents than simvastatin- and OIE-treated adipocytes. Moreover, the negative PC2 loading in the lipids region (centred at $2920 \mathrm{~cm}^{-1}$ and $2854 \mathrm{~cm}^{-1}, 1485 \mathrm{~cm}^{-1}$ ) suggest that preadipocytes and OIE-treated adipocytes exhibit different properties. These results are consistent with the second derivative spectra results mentioned in the previous section. 


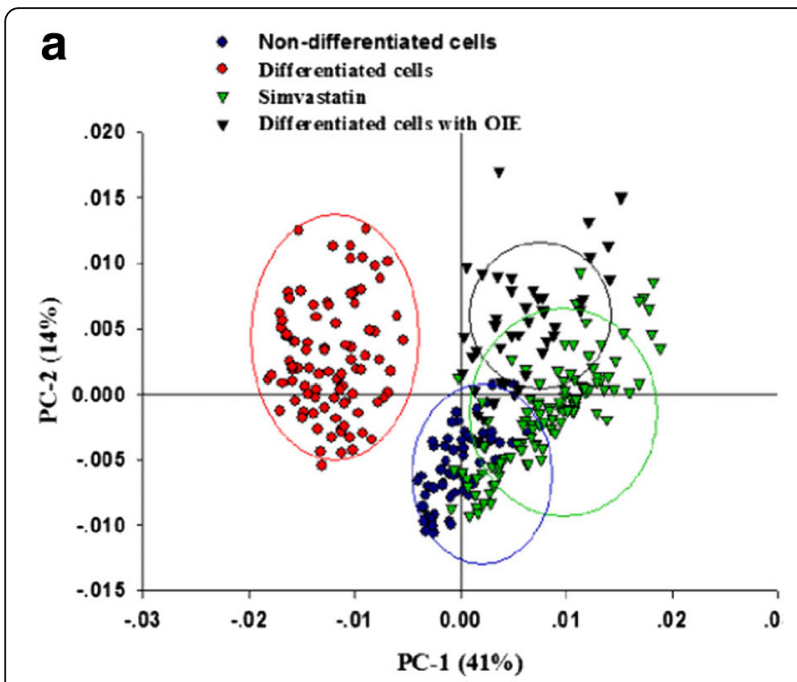

b

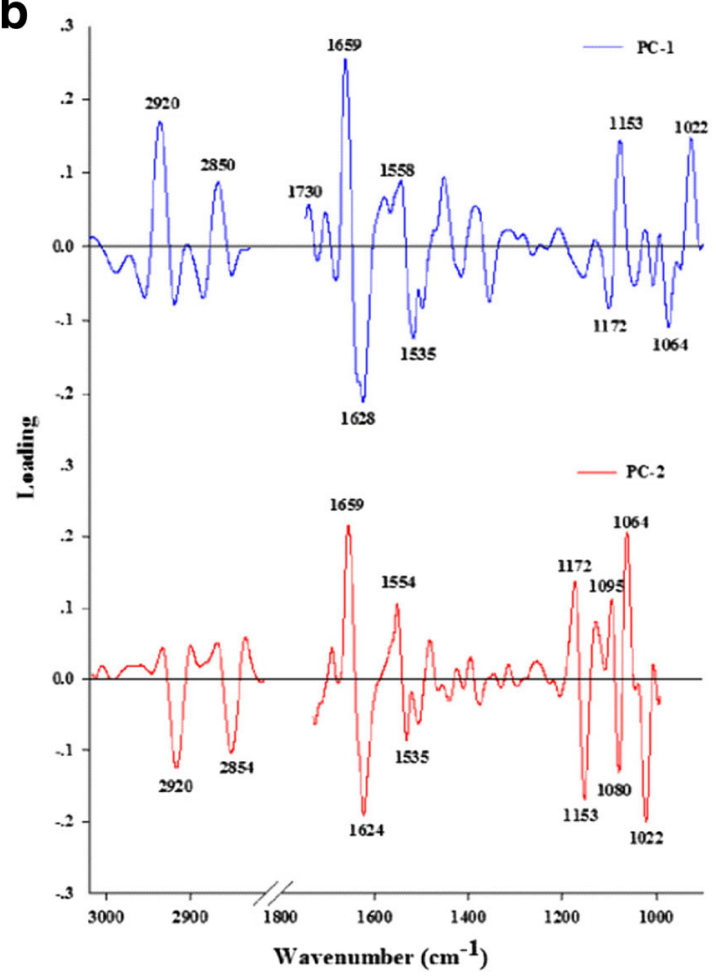

Fig. 8 Principal component analysis (PCA) of FTIR spectral ranges $3000-2800 \mathrm{~cm}^{-1}$ and $1800-950 \mathrm{~cm}^{-1}$ giving PCA score plot. The 2D PCA score plots showed the clustering separation spectra between 3T3-L1 non-differentiated cells, differentiated cells, simvastatin- and Oroxylum indicum extract-treated differentiated cells after 10 days (a). PCA loading plot (b). The biomarker differences over a spectral range of samples are identified by the PC1 and PC2 loading plots

\section{UHCA}

Unsupervised Hierarchical Cluster Analysis (UHCA) was used to determine the spectral similarity within groups and between groups of preadipocytes, untreated adipocytes, simvastatin- and OIE-treated adipocytes. The spectral similarity regarding relative distance is illustrated in the dendrogram (Fig. 9), which was obtained using second derivative spectral data and Ward's algorithm. In simple terms, the lower the heterogeneity, the more similarity exists between the groups. The UHCA analysis indicates that there is a distinct difference between pre-adipocytes and the other cell types. Further to this, the non-treated adipocytes are different from both OIE and simvastatin-treated cells. The results exhibited that the first cluster of pre-adipocyte, branch A, was clearly separated from other groups (branch B). Additionally, the branch $B$ that was corresponding to spectra of untreated adipocytes (branch B2), OIE-treated- (branch B1.1) and simvastatin-treated (branch B1.2) adipocytes was obviously distinguished. The spectra of branch B1 is composed of two subgroups revealing a closer similarity between OIE- and simvastatin-treated adipocytes. Cluster analysis employed Ward's algorithm using second derivatives, and vector normalization, over the spectral ranges 3000$2800 \mathrm{~cm}^{-1}$ and $1800-950 \mathrm{~cm}^{-1}$. Regarding the result in Fig. 7a, the lipid amount of pre-adipocytes as expected was the lowest $(p<0.05)$.

\section{Effect of the OIE on pancreatic lipase activity}

Pancreatic lipase is an enzyme responsible for the hydrolysis of lipid into free fatty acids and glycerol. OIE concentrations between 100 to $1250 \mu \mathrm{g} / \mathrm{mL}$ displayed significantly higher inhibitory lipase activity than those of the controls $(p<0.05)$ (Fig. 10). Moreover, the $\mathrm{IC}_{50}$ of OIE for the inhibition of pancreatic lipase was 1062.04 \pm $32.21 \mu \mathrm{g} / \mathrm{mL}$. Whilst the inhibitory effect of the positive control, orlistat at 12.5 to $100 \mu \mathrm{g} / \mathrm{mL}$, demonstrated an $\mathrm{IC}_{50}$ at $38.78 \pm 9.55 \mu \mathrm{g} / \mathrm{mL}$. Under those circumstances, the potential strength of orlistat on lipase activity inhibition is approximately 27 times greater than the OIE. These results suggest that the inhibition of pancreatic lipase activity by OIE increased in a dose-dependent manner.

\section{Discussion}

Adipocyte formation and activity appears to play a central role in the development of obesity. The generation and metabolism of adipocytes have become major targets for treating obesity [34]. One area that has increased is the use of natural products to target obesity. Compared to the convenience and cost they are becoming more attractive propositions than synthetic drugs or surgery $[35,36]$. In this study, we investigated the effects of an OIE on the anti-adipogenic and biomolecular change in 3T3-L1 cells. Our studies indicated there was a dose-dependent effect of OIE upon the viability of preadipocyte ranging from concentrations of $250 \mu \mathrm{g} / \mathrm{mL}$ to $1500 \mu \mathrm{g} / \mathrm{mL}$. At lower doses $(0-200 \mu \mathrm{g} / \mathrm{mL})$ there was no significant difference from the control $(p>0.05)$. Although no major impact on the viability of the cells was 


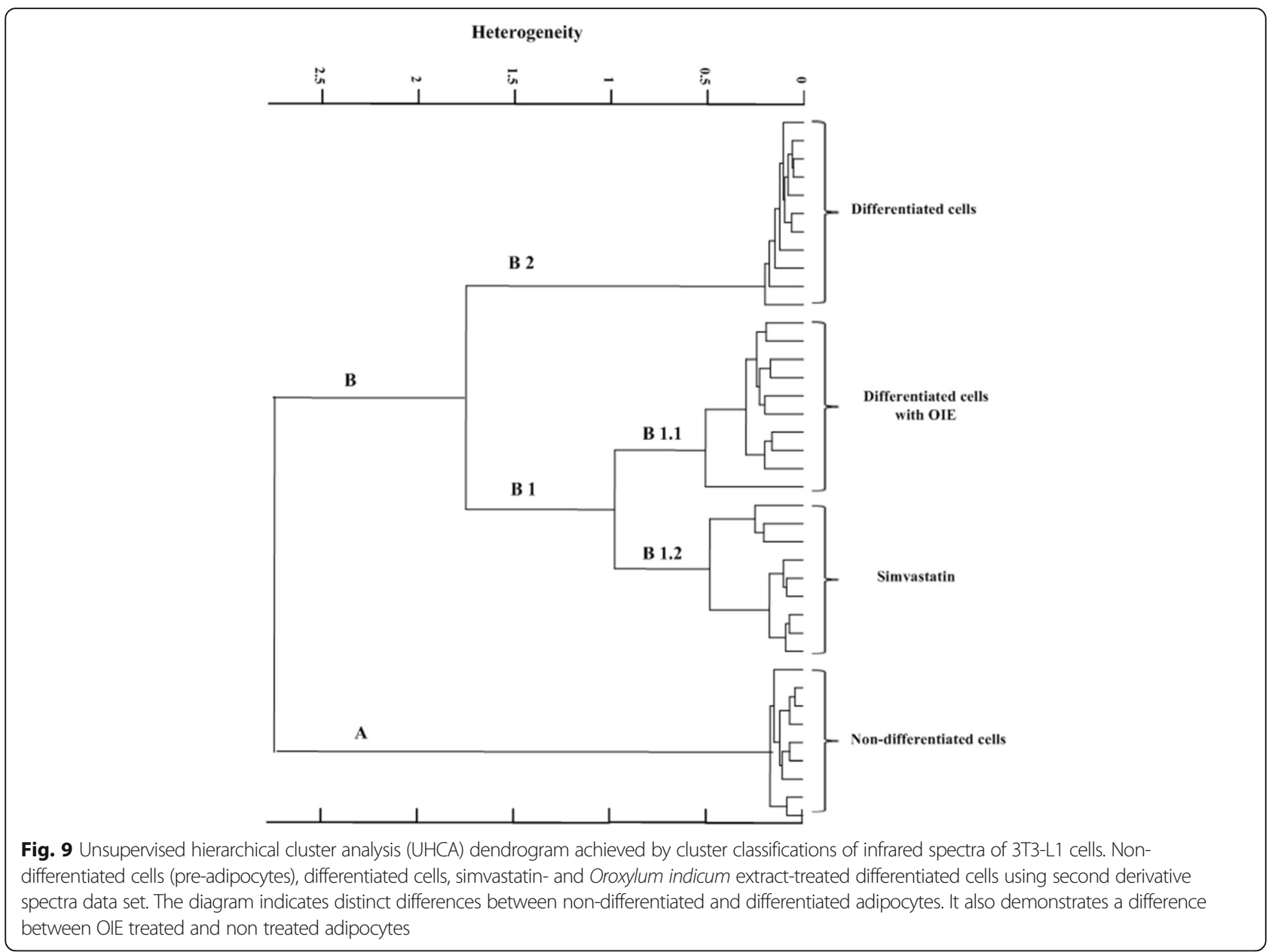

observed at lower doses, there may be some toxicological changes to the cells. One further observation was that doses of OIE between 50 to $200 \mu \mathrm{g} / \mathrm{mL}$ indicated a dose-dependent decrease of lipid accumulation in the adipogenesis assay (Figs. 3 and 4). One explanation for the reduction of lipid could be that the chemical components of OIE may have a potent effect which inhibits the differentiation of 3T3-L1 preadipocytes. A previous study reported that the fruit of $O$. indicum is rich in flavonoids such as baicalein [37]. At a concentration of $20 \mu \mathrm{M}$ baicalein can prevent the differentiation of preadipocyte to adipocyte during first 4 days of induction [38]. In fact, there is evidence to support that baicalein inhibits a cell cycle regulator, promoting cell cycle arrest at the G0/G1 phase. It was also reported to suppress the $\mathrm{m}$-TOR signaling pathway leading to an inhibition of adipogenic factors such as PPARY [39]. OIE at $200 \mu \mathrm{g} /$ $\mathrm{mL}$ lipid accumulation was not significantly different to cells treated with $1.67 \mu \mathrm{g} / \mathrm{mL}(4 \mu \mathrm{M})$ of simvastatin (Fig. 3, $p>0.05$ ). This was a very interesting observation as it confirms the observations made by Nicholson et al. They demonstrated that statins, such as pitavastatin and simvastatin at $5 \mu \mathrm{M}$ could inhibit adipocyte differentiation by blocking PPAR $\gamma$ expression and activating pref-1 expression [40]. These findings provide evidence that the OIE may also have the capacity to inhibit PPARY activity.

To further elucidate the biochemical potential of OIE, an in vitro pancreatic lipase assay was performed as part of this study. Lipase became a target for research groups attempting to prevent obesity or metabolic syndrome $[21,25]$. Pancreatic lipase is an enzyme responsible for the breakdown of triglycerides into glycerol and fatty acid in the gastrointestinal tract. When lipase activity is inhibited, triacylglycerol cannot cross the intestinal brush border membrane leading to a decrease in the uptake of lipids into the human body. Orlistat, a known lipase inhibitor is a drug for treating obesity was used in this study as a positive control. The results of this study indicated that OIE demonstrates as inhibition of pancreatic lipase between doses of $100-1250 \mu \mathrm{g} / \mathrm{mL}\left(\mathrm{IC}_{50}\right.$ of $1062.04 \pm 32.21 \mu \mathrm{g} / \mathrm{mL}), 27$ times less potent than orlistat. The dose of OIE that inhibited pancreatic lipase was also a concentration which induced a decrease in 


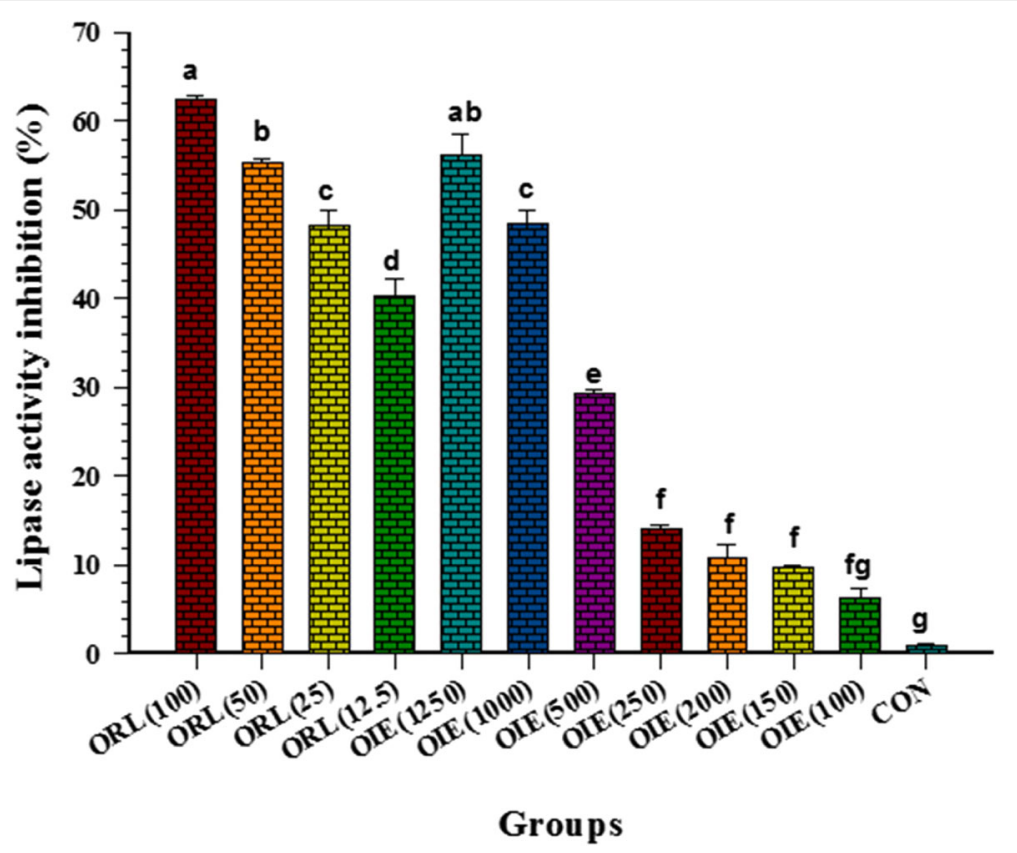

Fig. 10 Inhibitory effects of Oroxy/um indicum extract compare to Orlistat on lipase activity. CON=Control; OIE(100)= Oroxy/um indicum at $100 \mu \mu g / m L ; ~ O R L(12.5)=$ Orlistat at $12.5 \mu \mathrm{g} / \mathrm{mL}$. Orlistat was used as a positive control. Values are represented as Means \pm SEM $(n=3)$. A significant differences were observed (Tukey's HSD test, $p<0.05$ ) and are represented on the figure with letters from a to $\mathrm{g}$. Data suggests that Orlistat is 27 times more effective as inhibitor of lipase compared to OIE

viability of pre-adipocytes $\left(\mathrm{IC}_{50}\right.$ of $882.68 \pm 47.99 \mu \mathrm{g} /$ $\mathrm{mL})$. However, a study by Roh and Jung indicated a number of plant extracts could inhibit pancreatic lipase but had a very little effect on the viability of 3T3-L1 cells [41]. In the light of this publication, it would appear that OIE is not the most effective inhibitor of lipase activity. However, the potential for OIE to inhibit cell cycle progression [39] or its effects on key adipogenic biochemical pathways [16] still requires further investigation.

Although FTIR microspectroscopy has previously been used to characterise biochemical composition in medical research studies $[29,42,43]$. This is the first study using FTIR to demonstrate on the biochemical profile of OIE treated adipocyte. These results indicated that the lipids, lipid esters, nucleic acids, glycogen and carbohydrates of the OIE-treated adipocytes were significantly decreased compared to the untreated adipocytes (Fig. 7a and b). This study indicates that FTIR provided data similar to that obtained using established biochemical assays. This suggests that FTIR is a very useful technique for assessing the impact of plant extracts on established cell lines. Although FTIR supported the preliminary evidence regarding to biochemical changes during the differentiation of 3 T3-L1 cells more research is needed to clarify the mechanism of action of OIE.

\section{Conclusions}

This study suggests that the OIE derived from the fruit pods of the plant inhibited both adipogenesis and lipid accumulation in 3T3-L1 adipocytes. The extract inhibited lipase activity, but this was not as effective as orlistat. FTIR microspectroscopy provides valuable information which supported the biochemical assays used to assess 3T3-L1 cells. The precise mechanism of inhibitory effect on adipogenesis and lipid accumulation is of biochemical interest and requires further investigation.

\section{Abbreviations \\ ANOVA: One-way analysis of variance; DMEM: Dulbecco's modified Eagle's medium with high glucose; DMSO: Dimethyl sulphoxide; EMSC: Extended multiplicative signal correction; FTIR: Fourier transform-infrared; IBMX: 3- Isobutyl-1-methylxanthine; MTT: 3-(4,5-Dimethylthiazol-2-yl)-2,5- diphenyltetrazolium bromide; OIE: Oroxylum indicum extract; PCA: Principal Component Analysis; SEM: The standard error of the mean; TFC: Total flavonoids content; TPC: Total phenolic content; UHCA: Unsupervised Hierarchical Cluster Analysis}

\section{Acknowledgements}

The authors are grateful to the Synchrotron Light Research Institute (Public Organization), Thailand, for supporting the FTIR microspectroscopy technique.

\section{Funding}

The research was supported by the Thailand Research Fund through The Royal Golden Jubilee Ph.D. Program (Grant No. PHD/0029/2556). The sponsors had no influence in the design of the study, data collection, analysis, and interpretation of the data. They had no influence over the contents or organization of this manuscript and writing the manuscript.

\section{Availability of data and materials}

The datasets used and analysed during the current study are available from the corresponding author on reasonable request. 


\section{Authors' contributions}

TH designed the study, carried out all experiments, analysed and interpreted the data, drafted the initial and revised manuscript. GL conceived and designed the study, supervised data collection, critically reviewed and revised the manuscript. KTh and KTi participated in the designed, performed and interpreted of FTIR data, and wrote a manuscript of FTIR part. SS contributed in plant preparation and extraction, prepared chemical substances, and drafted the manuscript of these parts. GE designed the project, supervised the experiments, wrote and revised the manuscript. All authors have read and approved the final manuscript.

\section{Ethics approval and consent to participate} Not applicable.

\section{Competing interests}

The authors declare that they have no competing interests.

\section{Publisher's Note}

Springer Nature remains neutral with regard to jurisdictional claims in published maps and institutional affiliations.

\section{Author details}

${ }^{1}$ School of Preclinic, Institute of Science, Suranaree University of Technology, Nakhon Ratchasima 3000, Thailand. ${ }^{2}$ School of Pharmacy and Biomolecular Sciences, Liverpool John Moores Univerisity, James Parsons Building, Byrom Street, Liverpool L3 3AF, UK. ${ }^{3}$ Synchrotron Light Research Institute (Public Organization), Suranaree Subdistrict, Muang District, Nakhon Ratchasima 30000, Thailand.

\section{Received: 26 June 2017 Accepted: 30 May 2018}

\section{Published online: 08 June 2018}

\section{References}

1. Wang C, Chiang C, Yatsuya H, Hilawe EH, Ikerdeu E, Honjo K, et al, Descriptive epidemiology of hypertension and its association with obesity: based on the WHO STEPwise approach to surveillance in Palau. Asia Pac J Public Health. 2017; https://doi.org/10.1177/1010539517704042.

2. Kopelman PG. Obesity as a medical problem. Nature. 2000;404:635-43.

3. Ahmadian M, Duncan RE, Jaworski K, Sarkadi-Nagy E, Sul HS. Triacylglycero metabolism in adipose tissue. Future Lipidol. 2007;2:229-37.

4. Tchernof A, Despres JP. Pathophysiology of human visceral obesity: an update. Physiol Rev. 2013;93:359-404.

5. De Simone G, D'Addeo G. Sibutramine: balancing weight loss benefit and possible cardiovascular risk. Nutr Metab Cardiovasc Dis. 2008;18:337-41.

6. Thurairajah PH, Syn W-K, Neil DA, Stell D, Haydon G. Orlistat (Xenical)induced subacute liver failure. Eur J Gastroenterol Hepatol. 2005;17:1437-8.

7. Yun JW. Possible anti-obesity therapeutics from nature-a review. Phytochemistry. 2010;71:1625-41.

8. Ghorbani A, Hadjzadeh MA, Rajaei Z, Zendehbad SB. Effects of fenugreek seeds on adipogenesis and lipolysis in normal and diabetic rats. Pak J Biol Sci. 2014;17:523-8.

9. Dinda B, SilSarma I, Dinda M, Rudrapaul P. Oroxylum indicum (L.) Kurz, an important Asian traditional medicine: from traditional uses to scientific data for its commercial exploitation. J Ethnopharmacol. 2015;161:255-78.

10. Uddin K, Sayeed A, Islam A, Rahman AA, Ali A, Khan G, et al. Purification, characterization and cytotoxic activity of two flavonoids from Oroxylum indicum vent.(Bignoniaceae). Asian J Plant Sci. 2003;2:515-8.

11. Palasuwan A, Soogarun S, Lertlum T, Pradniwat P, Wiwanitkit V. Inhibition of Heinz body induction in an in vitro model and total antioxidant activity of medicinal Thai plants. Asian Pac J Cancer Prev. 2005;6:458-63.

12. Tran TV, Malainer C, Schwaiger S, Hung T, Atanasov AG, Heiss EH, et al Screening of Vietnamese medicinal plants for NF-kappaB signaling inhibitors: assessing the activity of flavonoids from the stem bark of Oroxylum indicum. J Ethnopharmacol. 2015;159:36-42.

13. Singh J, Kakkar P. Modulation of liver function, antioxidant responses, insulin resistance and glucose transport by Oroxylum indicum stem bark in STZ induced diabetic rats. Food Chem Toxicol. 2013:62:722-31.

14. Joshi SV, Vyas BA, Shah PD, Shah DR, Shah SA, Gandhi TR. Protective effect of aqueous extract of Oroxylum indicum Linn. (root bark) against DNBSinduced colitis in rats. Indian J Pharmacol. 2011;43:656-61.
15. Tamboli AM, Karpe ST, Shaikh SA, Manikrao AM, Kature DV. Hypoglycemic activity of extracts of Oroxylum indicum $(\mathrm{L})$ vent roots in animal models. Pharmacologyonline. 2011;2:890-9.

16. Singh J, Kakkar P. Oroxylin a, a constituent of Oroxylum indicum inhibits adipogenesis and induces apoptosis in 3T3-L1 cells. Phytomedicine. 2014;21: 1733-41.

17. Yadav R, Agarwala M. Phytochemical analysis of some medicinal plants. J Phytol. 2011;3:10-4.

18. Rauf A, Jan M, Rehman W, Muhammad N. Phytochemical, phytotoxic and antioxidant profile of Caralluma tuberculata NE Brown. J Pharm Pharmacol. $2013 \cdot 2 \cdot 21-5$

19. Kohoude MJ, Gbaguidi F, Agbani P, Ayedoun M-A, Cazaux S, Bouajila J. Chemical composition and biological activities of extracts and essential oil of Boswellia dalzielii leaves. Pharm Biol. 2017;55:33-42.

20. Jing LJ, Mohamed M, Rahmat A, Bakar MFA. Phytochemicals, antioxidant properties and anticancer investigations of the different parts of several gingers species (Boesenbergia rotunda, Boesenbergia pulchella var attenuata and Boesenbergia armeniaca). J Med Plants Res. 2010;4:27-32.

21. Dunkhunthod B, Thumanu K, Eumkeb G. Application of FTIR microspectroscopy for monitoring and discrimination of the anti-adipogenesis activity of baicalein in 3T3-L1 adipocytes. Vib Spectrosc. 2017;89:92-101.

22. Denizot F, Lang R. Rapid colorimetric assay for cell growth and survival. modifications to the tetrazolium dye procedure giving improved sensitivity and reliability J Immunol Methods. 1986;89:271-7.

23. Mandlik V, Patil S, Bopanna R, Basu S, Singh S. Biological activity of Coumarin derivatives as anti-leishmanial agents. PLoS One. 2016;11: e0164585.

24. Ramirez-Zacarias JL, Castro-Munozledo F, Kuri-Harcuch W. Quantitation of adipose conversion and triglycerides by staining intracytoplasmic lipids with oil red O. Histochemistry. 1992;97:493-7.

25. Guo X, Liu J, Cai S, Wang O, Ji B. Synergistic interactions of apigenin, naringin, quercetin and emodin on inhibition of 3T3-L1 preadipocyte differentiation and pancreas lipase activity. Obes Res Clin Pract. 2016;10: 327-39.

26. Cai $\mathrm{S}$, Wang $\mathrm{O}$, Wang $\mathrm{M}, \mathrm{He} J$, Wang $\mathrm{Y}$, Zhang $\mathrm{D}$, et al. In vitro inhibitory effect on pancreatic lipase activity of subfractions from ethanol extracts of fermented oats (Avena sativa L.) and synergistic effect of three phenolic acids. J Agric Food Chem. 2012;60:7245-51.

27. Garip S, Gozen AC, Severcan F. Use of Fourier transform infrared spectroscopy for rapid comparative analysis of Bacillus and Micrococcus isolates. Food Chem. 2009;113:1301-7.

28. Baloglu FK, Garip S, Heise S, Brockmann G, Severcan F. FTIR imaging of structural changes in visceral and subcutaneous adiposity and brown to white adipocyte transdifferentiation. Analyst. 2015;140:2205-14.

29. Vongsvivut J, Heraud P, Gupta A, Puri M, McNaughton D, Barrow CJ. FTIR microspectroscopy for rapid screening and monitoring of polyunsaturated fatty acid production in commercially valuable marine yeasts and protists. Analyst. 2013;138:6016-31.

30. Nara M, Okazaki M, Kagi H. Infrared study of human serum very-low-density and low-density lipoproteins. Implication of esterified lipid $\mathrm{C}=\mathrm{O}$ stretching bands for characterizing lipoproteins. Chem Phys Lipids. 2002;117:1-6.

31. Srisayam M, Weerapreeyakul N, Barusrux S, Tanthanuch W, Thumanu K. Application of FTIR microspectroscopy for characterization of biomolecular changes in human melanoma cells treated by sesamol and kojic acid. J Dermatol Sci. 2014;73:241-50.

32. Cao J, Ng ES, McNaughton D, Stanley EG, Elefanty AG, Tobin MJ, et al. The characterisation of pluripotent and multipotent stem cells using Fourier transform infrared microspectroscopy. Int J Mol Sci. 2013;14:17453-76.

33. Zohdi V, Whelan DR, Wood BR, Pearson JT, Bambery KR, Black MJ. Importance of tissue preparation methods in FTIR micro-spectroscopical analysis of biological tissues:'traps for new users'. PLoS One. 2015;10: e0116491.

34. Nawrocki AR, Scherer PE. Keynote review: the adipocyte as a drug discovery target. Drug Discov Today. 2005;10:1219-30.

35. Chang J. Medicinal herbs: drugs or dietary supplements? Biochem Pharmacol. 2000:59:211-9.

36. Clegg A, Colquitt J, Sidhu M, Royle P, Walker A. Clinical and cost effectiveness of surgery for morbid obesity: a systematic review and economic evaluation. Int J Obesity. 2003;27:1167-77.

37. Roy MK, Nakahara K, Na TV, Trakoontivakorn G, Takenaka M, Isobe S, et al. Baicalein, a flavonoid extracted from a methanolic extract of Oroxylum 
indicum inhibits proliferation of a cancer cell line in vitro via induction of apoptosis. Die Pharmazie. 2007;62:149-53.

38. Madsen L, Petersen RK, Sørensen MB, Jørgensen C, Hallenborg P, Pridal L, et al. Adipocyte differentiation of 3T3-L1 preadipocytes is dependent on lipoxygenase activity during the initial stages of the differentiation process. Biochem J. 2003:375:539-49.

39. Seo M-J, Choi H-S, Jeon H-J, Woo M-S, Lee B-Y. Baicalein inhibits lipid accumulation by regulating early adipogenesis and $\mathrm{m}$-TOR signaling. Food Chem Toxicol. 2014;67:57-64.

40. Nicholson AC, Hajjar DP, Zhou X, He W, Gotto AM Jr, Han J. Anti-adipogenic action of pitavastatin occurs through the coordinate regulation of PPARgamma and Pref-1 expression. Br J Pharmacol. 2007;151:807-15.

41. Roh C, Jung U. Screening of crude plant extracts with anti-obesity activity. Int J Mol Sci. 2012;13:1710-9.

42. Pijanka JK, Kumar D, Dale T, Yousef I, Parkes G, Untereiner V, et al. Vibrational spectroscopy differentiates between multipotent and pluripotent stem cells. Analyst. 2010;135:3126-32.

43. Manoharan R, Baraga JJ, Rava RP, Dasari RR, Fitzmaurice M, Feld MS. Biochemical analysis and mapping of atherosclerotic human artery using FT-IR microspectroscopy. Atherosclerosis. 1993;103:181-93.

Ready to submit your research? Choose BMC and benefit from:

- fast, convenient online submission

- thorough peer review by experienced researchers in your field

- rapid publication on acceptance

- support for research data, including large and complex data types

- gold Open Access which fosters wider collaboration and increased citations

- maximum visibility for your research: over $100 \mathrm{M}$ website views per year

At BMC, research is always in progress.

Learn more biomedcentral.com/submissions 